University of Nebraska - Lincoln

DigitalCommons@University of Nebraska - Lincoln

Faculty Publications, Department of Child, Youth, and Family Studies

Child, Youth, and Family Studies, Department of

2021

Strengthening the Quality of Preschool, Childcare, and Parenting

Soo-Young Hong

Holly Hatton-Bowers

Lisa Knoche

Follow this and additional works at: https://digitalcommons.unl.edu/famconfacpub

Part of the Child Psychology Commons, Developmental Psychology Commons, Early Childhood Education Commons, Family, Life Course, and Society Commons, Other Psychology Commons, and the Other Sociology Commons

This Article is brought to you for free and open access by the Child, Youth, and Family Studies, Department of at DigitalCommons@University of Nebraska - Lincoln. It has been accepted for inclusion in Faculty Publications, Department of Child, Youth, and Family Studies by an authorized administrator of DigitalCommons@University of Nebraska - Lincoln. 
Published as chapter 10 in Fostering the Emotional Well-being of Our Youth: A School-Based Approach (Philip J. Lazarus, Shannon M. Suldo, and Beth Doll, eds.), pp. 204-223. New York: Oxford University Press, 2021.

Copyright (C 2021 Oxford University Press. Used by permission.

\title{
Strengthening the Quality of Preschool, Childcare, and Parenting
}

\author{
Soo-Young Hong, Holly Hatton-Bowers, and Lisa Knoche \\ University of Nebraska-Lincoln, Lincoln, Nebraska, USA
}

Children have very deep feelings just the way parents do, just the way everybody
does, and our striving to understand those feelings and to better respond to them
is what I feel is the most important task in our world.
-Fred Rogers

Early childhood is a critical period during which children learn to regulate and manage emotions and actions, develop and maintain social relationships, and interact effectively with others (Scott-Little, Kagan, \& Frelow, 2006). Children who know how to use appropriate behavioral and emotional strategies and effectively interact with others are more likely to develop positive relationships and be accepted by peers later on (Odom, McConnell, \& Brown, 2008). Emotional well-being and competence is one of the key areas of development that goes through significant changes over the early childhood period (Hyson, Copple, \& Jones, 2006; Keane \& Calkins, 2004), and thus, researchers and practitioners in the field of early care and education add a significant emphasis on this area of development. Early learning guidelines and standards of most states in the United States include the domain of social-emotional development, and early childhood educators regularly assess and document children's developmental trajectories and progress of emotional competence (Oberle \& Schonert-Reichel, 2017; Scott-Little et al., 2006). In this chapter, we describe supports for young children's emotional well-being and positive behavior, promising strategies and interventions used in early care and education settings, the well-being of early childhood educators ${ }^{1}$ that impacts children's emotional competence, and the importance of engaging families in promoting children's emotional well-being and positive behavior. 


\section{Young Children's Emotional Well-being and Positive Behavior}

Foundational knowledge and skills on which children can build emotional well-being and competence are captured in the systemic Collaborative for Academic, Social, and Emotional Learning (CASEL) framework. The framework includes self-awareness (e.g., identifying emotions, self-confidence, accurate self-perception), social-awareness (e.g., perspectivetaking, empathy, respect for others, appreciating diversity), relationship skills (e.g., communication, social engagement, teamwork), self-management (e.g., impulse control, goalsetting, self-motivation), and responsible decision-making (e.g., analyzing situations, reflecting, identifying problems; Weissberg, Durlak, Domitrovich, \& Gullotta, 2015). Opportunities that help children identify, interpret, and express emotions are closely linked to developing positive social and behavioral outcomes (Maguire, Niens, Mccann, \& Connolly, 2015; Russell, Lee, Spieker, \& Oxford, 2016) and, in turn, successful academic outcomes (Downer \& Pianta, 2006).

Emotion regulation has been significantly associated with emotional health and well-being, cognitive development, and later academic achievement (Djambazova-Popordanoska, 2016). Emotional health and well-being can be understood by examining individuals' mood (i.e.; positive or negative feelings), their ability to regulate emotions, and their self-esteem (i.e., feeling of self-worth; Blandon, Calkins, \& Keane, 2010; Djambazova-Popordanoska, 2016). These aspects of emotional competence, in turn, impact the individual's social competence (Denham et al., 2003). Therefore, to promote young children's emotional well-being and competence, it is important to help them identify and manage their own emotions and learn to appropriately identify and respond to the emotions of others, such as their peers. As such, early childhood educators and families play a critical role in supporting young children's acquisition of emotional well-being and social competence.

In childcare settings, early childhood educators often expect children to follow directions, interact with peers, and begin to effectively manage their emotions (Denham \& Brown, 2010). However, a common challenge for early childhood educators is caring for children who use few appropriate strategies for managing their emotions and behaviors. Having this support from caregivers is particularly important for young children who experience developmental risks, who struggle with their social and emotional skills, and/or who live in disadvantaged environments. Children who experience behavioral and emotional challenges can be treated punitively by early childhood educators and, in some cases, be expelled from their preschool (Gilliam, 2008), which further exacerbates social and emotional challenges for these children. Specifically, children who exhibit challenging behaviors in preschool are three times more likely to be expelled than students at grades K-12 (Gilliam, 2010). These challenges may be further intensified for children living in lowincome environments. Children living in low-income families and disadvantaged neighborhoods may face diminished emotional well-being and competence, which often leads to negative future outcomes, such as poor education, unemployment, substance use, and poor mental health (Robert Wood Johnson Foundation, 2016). Risk factors most often associated with these negative outcomes are families' limited access to social and financial supports (Cooper, 2009), which may include not having access to consistent high-quality health care, healthy foods, affordable housing, and/or transportation (Jarrett \& Coba- 
Rodriguez, 2015). It is common for parents from low-income households to work night shifts or have more than one job (Enchautegui, 2013), which can limit their access to school events and opportunities that can serve to support young children's social-emotional development and learning. These family risks and circumstances, collectively, can lead to adverse impacts on young children's developing school readiness skills. If a young child is hungry, not getting quality sleep, and not receiving the support needed from caregivers, it becomes challenging for the child to learn and apply healthy social-emotional skills.

While young children living in low-income families are at greater risk of developing poorer emotional competence and school readiness skills, these children often experience the greatest gains or improvements as a result of participating in a social-emotional learning (SEL) intervention (Bailey, Duncan, Odgers, \& Yu, 2017). Ongoing research is directed toward identifying the specific components of early childhood interventions that directly impact young children's positive emotional and behavioral outcomes. Existing research provides clear evidence that the quality of early care and education that young children receive plays a crucial role in ameliorating challenging behaviors and promoting emotional well-being and positive behaviors. In the following section, we discuss important aspects of early care and education quality associated with positive emotional and behavioral outcomes in young children.

\section{Childcare Quality Associated with Emotional Well-being and Positive Behavior}

Over 20 years of research supports the importance of children's SEL for later well-being (Weissberg el al., 2015). While families typically have the most impact for promoting children's emotional well-being and competence, high-quality early care and education environments have become increasingly important for young children's learning, health, and well-being; approximately $80 \%$ of young children spend time in nonparental care (Snyder \& Dillow, 2015). High-quality early learning environments provide safety, enrichment, and stimulation that foster children's learning and growth.

Defining quality can be complicated, as it consists of both process (i.e., interactional and relationship-based) and structural aspects (i.e., environmental characteristics of the care setting). An important structural aspect of childcare quality negatively associated with children's emotional well-being and competence includes noise and environmental chaos. Noise in early childhood settings is negatively associated with children's emotional wellbeing (Werner, Linting, Vermeer, \& IJzendoorn, 2015), and children enrolled in more chaotic preschools exhibit less compliant behaviors (Wachs, Gurkas, \& Kontos, 2004). The intensity, variability, and duration to which children are exposed to environmental chaos influence their development (Evans, 2006).

Positive, consistent interactions that children have with adults and their peers are among the process aspects of quality that facilitate emotional well-being and children's positive behaviors and are important predictors of development (Burchinal, Zaslow, Tarullo, \& Martinez-Beck, 2016). High-quality care is evidenced by sensitive, responsive, and attuned educators who show high regard for children and their feelings. In high-quality environments, young children experience safety, security, and rich learning opportunities where educators extend and scaffold children's thinking and learning (Cochran, Cochran, 
\& Torp, 2000; Thompson, 2016). Relationships high in responsiveness can promote positive interactions that foster healthy brain development (Shonkoff et al., 2012) and provide experiences for developing social-emotional competence and learning positive behaviors.

High-quality childcare may be particularly beneficial for promoting the social-emotional competence of children from low-income families, including those living in less stimulating home environments (Watamura, Phillips, Morrissey, McCartney, \& Bub, 2011), yet children from low-income homes are less likely to receive high-quality care. This can then create significant opportunity gaps related to early childhood development and learning. What is promising is that SEL intervention programs and supports can mitigate some of the barriers experienced by children from low-income families by providing important learning opportunities and resources.

\section{Promoting Emotional Competence and Positive Behavior in Childcare Settings}

Promoting children's emotional competence in childcare settings requires attention at a systems level; children participate in classroom programming, and classrooms are typically embedded within a larger childcare structure comprised of multiple classrooms. Therefore, centerwide interventions are critical as are interventions targeted at the classroom level. SEL (see chap. 5 in Fostering the Emotional Well-being of Our Youth) and positive behavior interventions and support (see chap. 4 in Fostering) are universal preventative frameworks that promote prosocial classroom climates in the entire school or center. SEL teaches young children emotion management skills and prompts healthy interactions and positive relationships thus enhancing children's motivation to learn (Oberle \& SchonertReichl, 2017; Schonert-Reichel \& Hymel, 2007). Positive behavior interventions and support is focused on reducing or preventing behavioral challenges and can be delivered at a centerwide, classroom, or individual level. In a recent meta-analysis that included 23,098 participants ranging in age from 2 to 17 years $(n=6,566$ [28.5\%] preschool age), interventions focused on improving children's self-regulation resulted in consistent improvements which further resulted in more prosocial classroom climates (Pandey et al., 2018). These studies used randomized clinical trials and cluster randomized trials. The strategies used to promote children's self-regulation included curricula that provided storytelling, circletime games, and self-talk. The results lend credence to the idea that the efforts to promote children's SEL are meaningful and worthwhile. Moreover, such efforts strengthen quality in early care and education settings.

At the classroom level, relational pedagogy encourages educators to use strategies that facilitate attunement, such as sensitivity, responsiveness, warmth, and consistent behavioral expectations (Hamre \& Pianta, 2001). These strategies are particularly important for supporting children's self-regulation and autonomy in learning. Furthermore, reduced stress in the classroom promotes a more positive and prosocial classroom climate (Pianta et al., 2005) by providing children with more opportunities to learn and use healthy emotional regulation strategies (see chap. 13 in Fostering). Some additional evidence-based and promising approaches to enhance and promote early childhood educators' support for children's emotional and behavioral well-being are PATHS (Kusche \& Greenberg, 1994); the pyramid model (Fox, Dunlap, Hemmeter, Joseph, \& Strain, 2003), mindfulness-based 
curricula, Early Childhood Mental Health Consultation (ECMHC), and combined coaching-consultation strategies such as the Learning to Objectively Observe Kids (LOOK) intervention.

\section{PATHS ${ }^{\circledR}$ Preschool/Kindergarten Classroom Module}

PATHS $^{\circledR}$ (Kusche \& Greenberg, 1994) is an evidence-based program that promotes children's social and emotional competence through the creation of a positive classroom learning environment. The program aims to improve children's self-control, self-esteem, emotional awareness, basic problem-solving skills, and social skills. The effectiveness of PATHS has been established in multiple studies showing improved emotion knowledge skills, greater social competence, and reduction in social withdrawal (Domitrovich, Cortes, \& Greenberg, 2007; Hamre, Pianta, Mashburn, \& Downer, 2012). When combined with a literacy intervention, children also showed higher engagement in learning, improved emotional knowledge and interpersonal problem-solving skills, and reduced aggression reported by teachers (Bierman, Domitrovich et al., 2008; Bierman, Nix, Greenberg, Blair, \& Domitrovich, 2008). The family component of PATHS extends learning at home with materials for families that directly relate to what children are learning in the classroom. Additionally, early childhood educators are encouraged to invite parents into the classroom to observe PATHS lessons.

\section{The Pyramid Model}

The Pyramid Model for Promoting Social-Emotional Competence (Hemmeter, Snyder, Fox, \& Algina, 2016) uses a multitiered system of support to develop early childhood educators' knowledge and skills to promote young children's SEL and positive behaviors. The model consists of three tiers built on the foundation of an effective workforce. Tier 1 consists of universal approaches that all early childhood educators can implement to foster safe, warm, nurturing relationships. Tier 2 strategies are targeted approaches used for children who evidence delays or challenges in their social-emotional skills and are at risk of developing more serious challenging behaviors. Tier 3 includes individualized interventions delivered to children who exhibit more persistent challenging behaviors. These children will receive frequent exposure and concerted interventions along with persistent monitoring to address the challenging behaviors. The pyramid model is disseminated by the Center on Social Emotional Foundations of Early Learning. While there is limited evidence of the effectiveness of each distinct tier of the pyramid model, there is evidence that early childhood educators who participate in the professional development trainings and coaching use more responsive strategies that are associated with children's use of more positive behaviors (Han, 2014; Hemmeter et al., 2016). More research is needed to understand how and why pyramid professional development and coaching result in children's emotional well-being and positive behaviors. Doing so will aid efforts to better understand and target teacher behaviors that are malleable and lead to positive changes in young children's SEL. 
HONG, HAtTOn-BOWERs, And KnOche, "Strengthening the Quality" (2021)

\section{Mindfulness}

Mindfulness-based curricula delivered to preschools are an emerging approach consisting of interpersonal and intrapersonal dimensions to promote SEL, reduce behavioral challenges, and promote teacher well-being. While there are many definitions for mindfulness, these curricula typically teach children and teachers to listen with full attention and with an attitude of curiosity, kindness, and flexibility. Children and teachers often are guided to engage in practices that promote nonjudgmental acceptance, compassion for self and others, self-regulation, and emotional awareness. At primary grades, practicing mindfulness has been particularly beneficial for students who initially evidenced lower cognitive functioning and social-emotional well-being. For example, children who initially demonstrated lower levels of executive functioning had improvement in executive functioning after learning the mindfulness strategies (Flook et al., 2010). While these studies are promising, there is limited research supporting the generalizability of mindfulness-based curricula as a way to enhance social-emotional well-being among preschool-aged children (e.g., the Kindness Curriculum; Flook, Goldberg, Pinger, \& Davidson, 2014). These mindfulness-based approaches are feasible and acceptable, but important questions remain about the impacts of teaching mindfulness on children's learning and emotional competence (Semple, Droutman, \& Reid, 2017).

\section{Early Childhood Mental Health Consultation}

ECMHC (Conners-Burrow, Whitehead-Mansell, Mckelvey, Virmani, \& Sockwell, 2012; Perry, Allen, Brennan, \& Bradley, 2010) is also a promising strategy for facilitating young children's emotional well-being and use of positive behaviors. In ECMHC, a mental health clinician works with early childhood educators to support children's social-emotional development by engaging in collaborative problem-solving and using strategies to enhance relationships between educators and children. ECMHC can also enhance the reflective capacities of an early childhood educator and reduce their stress. A randomized study with 88 preschool classrooms in Connecticut revealed that early childhood educators who received the ECMHC reported significantly lower ratings on children's externalizing and problem behaviors as compared to those in the wait-listed comparison group (Gilliam, Maupin, \& Reyes, 2016).

\section{Learning to Objectively Observe Kids}

LOOK (Downer et al., 2018) is a comprehensive consultation model for addressing children's challenging behaviors in the preschool classroom. Preschool teachers are asked to complete online modules and participate in a video-based feedback process. Assessments of children's behavior and engagement in the classroom are also used to help identify evidence-based social-emotional strategies for the teacher to use to address the challenging behaviors. LOOK also uses strategies from practice-based coaching wherein preschool teachers are asked to engage in a cycle of joint planning, observation, and reflection. Head Start teachers who participated in the LOOK intervention used more social-emotional teaching strategies and reported greater confidence to handle children's challenging behaviors. Children also evidenced fewer teacher- and observer-rated negative interactions with their educators and peers. 
HONG, HAtTOn-BOWERs, And KnOche, "Strengthening the Quality" (2021)

\section{Addressing the Well-being of Early Childhood Educators}

Evidence-based intervention strategies are available for promoting young children's emotional well-being and competence. However, questions remain about broader systemic issues that impact children's emotional well-being and competence and how these systemic variables might make interventions more effective. An important factor to consider when planning and providing interventions is the well-being of the early childhood educator. A useful conceptual model emphasizing the elements of whole teacher well-being addresses four dimensions critical for promoting the well-being of early childhood educators: physical well-being, psychological well-being, professional well-being, and workplace support (Kwon et al., 2019). All of these components are considered to be important for promoting the well-being of early childhood educators; however, for purposes of this chapter and our focus on malleable factors related to young children's emotional competence and positive behaviors, we discuss early childhood educators' psychological well-being and workplace supports.

\section{Psychological Well-Being}

Effective early childhood supports and strategies can become compromised by educator burnout and turnover. Although teachers in the early childhood sector experience high levels of personal reward, they also are susceptible to high levels of occupational stress, depression, and emotional burnout (Becker, Gallagher, \& Whitaker, 2017). Focusing on well-being is imperative for retention (Price \& McCallum, 2015), attraction to the profession, and teacher eftectiveness (Cook et al., 2017). The well-being of early childhood educators is also important for supporting children's well-being, particularly for children with behavioral and mental health challenges (Sisask et al., 2014). Emotionally regulated teachers tend to be self-aware of their emotional reactions, recognize and respond to behavioral and emotional cues in individual students, and engage in more sensitive and supportive interactions, while creating a positive feedback loop that contributes to self-regulation in both children and teachers (Jennings, 2015). In contrast, teachers with higher levels of depression and stress are less likely to show emotional sensitivity toward children (Goelman \& Guo, 1998; Hamre \& Pianta, 2004). In addition, teacher depression and financial distress have been linked to increased levels of negative, challenging child behavior (King et al., 2016; Roberts, LoCasale-Crouch, Hamre, \& Decoster, 2016).

A promising approach to address the emotional well-being of early childhood educators is mindfulness and reflection. Increased awareness and acceptance of one's own thoughts and feelings (i.e., mindfulness) has been linked to lower levels of teacher depression and workplace stress as well as to higher-quality teacher-child relationships in preschool classrooms (Becker et al., 2017; Jennings, 2015). To address the need to promote the well-being of teachers, a mindfulness-based reflection program, Cultivating Healthy Intentional Mindful Educators (CHIME), was piloted with 54 early childhood teachers (Hatton-Bowers et al., 2018). CHIME draws upon Jenning and Greenberg's (2009) model for a prosocial classroom and is delivered over eight weeks in small groups wherein educators are asked to participate in weekly formal and informal mindfulness practices at work and at home. Additionally, participants are asked to engage in "listening to understand" and 
journal reflection activities. The "listening to understand" activities consist of learning how to be patient and fully present during conversations and interactions with children, colleagues, and parents. The pilot study found significant positive effects on early childhood educators' perceived stress, general health, mindfulness, burnout, and sleep quality. CHIME is an intervention showing promising evidence to reduce early childhood educator's stress and to promote their well-being. It will be important for early care and education programs adopting this type of educator-focused well-being intervention to establish programmatic efforts that help make these practices and their impact sustainable.

\section{Workplace Supports}

Included in the workplace supports component for educator well-being are the physical environment, the work climate, compensation and benefits, and having designated breaks (Kwon et al., 2019). As such, organizational-level interventions may be beneficial in proactively addressing educator well-being by addressing the work climate.

One organizational approach is creating and engaging in professional learning communities. Early childhood centers could create professional learning communities around well-being and support professional learning with peers. Such communities provide a supportive context for facilitating reflection and ongoing learning that is engaging and individualized (Owen, 2016). Another critical workplace support is the educator compensation. Early childhood educators are known to be "among the lowest-paid workers" in the United States; this low pay tends to cause greater turnover in workforce (Phillips, Austin, \& Whitebook, 2016, p. 140) and increased stress, which negatively impacts the stability of care for young children (Morgan, 2019). This limited or lack of workplace support can adversely impact psychological well-being and the quality of care that young children receive. One significant predictor of early childhood educators' intention to stay in early childhood teaching is their motivation (Torquati, Raikes, \& Huddleston-Casas, 2007), which is significantly associated with endorsing child-centered beliefs, beliefs about developmentally appropriate practices, and lower job stress (Jeon, Kwon, Walsh, Burnham, \& Choi, 2019). Adequate compensation may help educators remain motivated to stay in the early childhood teaching field. This longevity allows educators to support young children's emotional well-being by building their capacities to provide young children with high-quality care as well as improving the stability of care for young children. Considering clear evidence that the well-being of educators is critical for optimizing later outcomes for children's emotional well-being and competence, we have a responsibility to advocate for high-quality care that addresses the well-being needs of early childhood educators as well.

\section{Promoting Emotional Well-being and Positive Behavior through Parent Engagement}

Families play a significant role in the development of young children's emotional health and well-being. Specifically, the parent-child relationship has been implicated through decades of research as having significant effects on children's early development (Ma, Shen, Krenn, Hu, \& Yuan, 2016). Parental caregiving patterns that are characterized by responsiveness, encouragement, and support are important for fostering children's feelings of safety and security (Edwards, Sheridan, \& Knoche, 2010) and, ultimately, children's 
emotional well-being. Early, positive interactions between parents and young children that are stimulating and nurturing promote neural connections and brain development that is essential for young children's academic success and emotional competence (Landry, Smith, \& Swank, 2003). In addition, parents' ability to regulate and manage children's emotions is an important predictor of children's emotional competence. Emotional coaching provides parents with the opportunity to become attentive to their child's emotions and help their child cope with negative emotions (Cottman, Katz, \& Hooven, 1996; Loop \& Roskam, 2016; Meyer, Raikes, Virmani, Waters, \& Thompson, 2014).

Relationships between parents and early childhood educators are essential in promoting children's positive development. These relationships early in a child's life create a system of meaningful support that facilitates social and emotional development. Early childhood educators are often the first professional outside of the home with whom parents interact regarding their child's education and development, and as such are uniquely positioned to establish constructive roles and relationships with parents. Quality parenteducator relationships strive to create continuity across settings (see chap. 11 in Fostering). Specifically, positive and constructive parent-educator relationships characterized by mutuality, warmth, and respect are associated with young children's academic performance and social-behavioral outcomes (Powell, Son, File, \& San Juan, 2010). Furthermore, partnerships in early childhood greatly enhance the amount, quality, and scope of services available to assist children in meeting their learning and behavioral goals (Clarke, Sheridan, \& Woods, 2009), particularly for children exhibiting social and emotional challenges.

Family engagement ${ }^{2}$ in early childhood settings, therefore, is a more general concept than traditional parent/family involvement. Parent involvement tends to be unidirectional, with messages originating from the center and extending to homes. Families are given directions for supporting their children's learning and emotional development; they are expected to coordinate with and participate in center activities and events. Alternatively, in a broader conceptualization of family engagement, parents and early childhood educators share important roles in supporting children's emotional health whereby communication is bidirectional and mutually responsive. Collaborative parent-educator partnerships are a critical component of strong early childhood programming designed to benefit young children's emotional health.

\section{Collaborative Partnership in Supporting Children's Emotional Well-Being}

Early intervention and prevention models that focus on partnerships with families often have as their foundation a family-centered philosophy. Family-centered services aim to provide opportunities for parents and other family members to demonstrate their abilities to (a) recognize children's development, needs, and interests; (b) recognize pertinent learning opportunities in routine and preferred everyday activities; and (c) use or develop their own skills, interests, and abilities to support and implement plans to guide their children's growth in the context of family beliefs and values.

A collaborative partnership approach takes advantage of the multiple perspectives and vantage points of both early childhood educators and parents. Collaborative partnerships emphasize the unique perspectives and expertise offered by parents and early childhood educators to address mutually determined goals for children and families (Friend \& Cook, 
2006). In a partnership model, child observations as well as ideas, opinions, values, and priorities are shared among parents and educators (Dunst \& Espe-Sherewindt, 2016; Hanft, Rush, \& Shelden, 2004). Collaboration allows educators and family members to pool knowledge and skills related to both process (i.e., how to best support children's emotional health) and content (i.e., identifying primary or priority developmental skills), which results in more comprehensive, effective, and efficient programming to support children and advocate for high-quality and collaborative early care and education. Family members are experts on knowing children's natural learning environments, children's strengths and interests, and the natural routines and schedules that children keep, whereas early childhood educators have expert information on recommended and/or evidence-based practices in child development and early childhood education. These shared inputs determine the direction of decision-making and allow for the mutual selection and/or design of intervention strategies for use at home and center to benefit and support children's emotional wellbeing. Collectively, parent and professional perspectives yield plans and developmental goals that are most fitting and productive for children and their parents. When beliefs and practices of families and early childhood educators related to process and content are congruent, improved child outcomes have been reported (Barbarin, Downer, Odom, \& Head, 2010).

The meaningful involvement of parents in joint action planning, ongoing problem-solving and decision-making relative to children's services has been shown to increase family ownership, sense of control, and commitment to intervention goals (Dunst \& Dempsey, 2007). Additionally, active participation by family members in the assessment and planning phases increases parental sense of control and commitment during the intervention stage, thereby increasing the likelihood of child progress (Trivette, Dunst, Boyd, \& Hamby, 1996). Furthermore, this joint decision-making can result in positive perceptions of early childhood educators on the part of families, which can result in a greater benefit from intervention services (Korfmacher, Green, Spellman, \& Thornburg, 2007). Two evidence-based and promising approaches that focus on enhancing and promoting parents' knowledge and abilities to support children's emotional well-being and development of positive behaviors are the Incredible Years program and the Getting Ready intervention.

\section{Incredible Years Program}

The highly researched Incredible Years program (Webster-Stratton, 1992) includes comprehensive, developmentally based curricula for children via Dinosaur School. A complement to the classroom programming, the Incredible Years Early Childhood Parent Training Programs, consists of structured 12 to 20 weekly group sessions of two to three hours each that teach parents important precursors for children's social and emotional development, including nurturing relationships, strengthening parent-child interactions, and reducing harsh discipline techniques via a video-mediated or small group training format. The content is grouped in four age categories (i.e., 0-12 months, 1-3 years, 3-6 years, and 6-12 years). The program's content areas are organized into four components: (a) strengthening children's social skills, emotional regulation and school readiness skills; (b) using praise and incentives to encourage cooperative behavior; (c) rules, routines, and effective limit setting; and (d) handling misbehavior. It includes nine DVDs, a self- 
administered manual, comprehensive leader manuals, weekly "refrigerator notes," parent homework assignments, and other support materials. The Incredible Years series has been extensively researched to determine its efficacy with children with conduct disorders, oppositional defiant disorders, and attention deficit/hyperactivity disorders, among others. Several studies using rigorous experimental procedures have found that the Incredible Years Program produces positive attitudinal and behavioral outcomes for both parents and children (e.g., Webster-Stratton, 1998; Webster-Stratton, Reid, \& Stoolmiller, 2008). Positive effects of the parenting program have been reported via meta-analysis (Menling, Orobio de Castro, \& Matthys, 2013).

\section{Getting Ready Intervention}

The Getting Ready intervention (Sheridan, Marvin, Knoche, \& Edwards, 2008) is used within existing community agencies and early childhood programs and focuses on the dual-relational contexts important in a young child's life - the parent-child and the parenteducator relationships - to promote school readiness for young children birth to five years. Rather than a parenting curriculum or parent training program per se, the Getting Ready intervention joins the expertise of parents with that of the early childhood educators, bringing together family contributions about relevant experiences and professional contributions about developmentally important activities. The collaborative nature of the process encourages parents and early childhood educators to share their respective observations and knowledge, to mutually identify relevant targets that support the child's abilities and emerging skills, and to enhance parent-child interaction. The Getting Ready intervention is procedurally operationalized via a set of strategies used flexibly and responsively in natural parent-child and parent-educator interactions, including those that are unstructured (e.g., drop-off/pick-up times, notes home) and structured (e.g., home visits, parentteacher conferences). The Getting Ready strategies are based on triadic consultation (McCollum \& Yates, 1994) that establishes and strengthens relationships and collaborative parent-teacher partnership interventions (Sheridan \& Kratochwill, 2008) that guide shared goal setting and decision-making. The strategies are related to effective interactions between early·childhood educators and families (Knoche, Marvin, \& Sheridan, 2015). In a previous randomized controlled trial of 220 preschool children, Getting Ready yielded positive results on children's social-emotional skills and behavioral competencies. Children demonstrated increased attachment behaviors with adults, improved initiative, and reduced anxiety/withdrawal behaviors (Sheridan, Knoche, Edwards, Bovaird, \& Kupzyk, 2010) and decreased overactive behaviors with parents (Sheridan et al., 2014). Positive effects on parenting behaviors were also observed (Knoche et al., 2012).

\section{Conclusion}

Early childhood is a critical period during which children learn to regulate and manage emotions and actions, develop and maintain social relationships, and interact effectively with others (Scott-Little et al., 2006). This chapter provides early childhood educators and families with young children information on research-based strategies and supports for enhancing children's emotional well-being and positive behaviors. We realize that many 
intervention efforts reach young children only in center-based early childhood settings because those are the settings where interventions have been implemented. We continue to observe opportunity gaps in children and families with limited access to those programs, which provide implications for building an early childhood program and services infrastructure that is more accessible and affordable for all families with young children.

In addition, the issue of children's emotional well-being and competence needs to be viewed using a systemic lens. Specifically, children's emotional outcomes should be understood in relation to structural and process aspects of childcare quality, families as critical partners, and early childhood educators as advocates and important stakeholders. Collaborative partnerships between parents and early childhood educators allow for an increased range and diversity of expertise and resources available to support children's development and functional competencies across developmental domains (e.g., social, behavioral, cognitive) and settings (e.g., home, childcare, community). In particular, collaboration yields interventions that are grounded in the strengths of all participants - parents, children, and early childhood educators-and ultimately are more likely to result in desired success (Chao, Bryan, Burstein, \& Ergul, 2006). Investigating and improving the overall early childhood infrastructure in our society is critical, especially for children living in low-income environments. Enhancing the development of young children's emotional competence will ultimately affect all aspects of their lives.

\section{Notes}

1. "Early childhood educators" refers to adults providing care for children in early care and education settings. Most of the research findings discussed in this chapter relate to those providing this type of care in center-based settings.

2. The term "family engagement" is used to recognize that there is a multiplicity of adults (e.g., grandparents, aunts, cousins, siblings, etc.), in addition to parents, who are actively involved in caregiving responsibilities and decision-making related to the child's well-being.

\section{References}

Bailey, D., Duncan, G. J., Odgers, C. L., \& Yu, W. (2017). Persistence and fadeout in the impacts of child and adolescent interventions. Journal of Research on Educational Effectiveness, 10, 7-39.

Barbarin, O., Downer, J., Odom, E., \& Head, D. (2010). Home-school differences in beliefs, support, and control during public pre-kindergarten and their link to children's kindergarten readiness. Early Childhood Research Quarterly, 25, 358-372. doi:10.1016/j.ecresq.2010.02.003

Becker, B. D., Gallagher, K. C., \& Whitaker, R. C. (2017). Teachers' dispositional mindfulness and the quality of their relationships with children in Head Start classrooms. Journal of School Psychology, $65,40-53$.

Bierman, K. L., Domitrovich, C. E., Nix, R. L., Gest, S. D., Welsh, J. A., Greenberg, M. T., \& Gill, S. (2008). Promoting academic and social-emotional school readiness: The Head Start REDI program. Child Development, 79, 1802-1817.

Bierman, K. L., Nix, R. L., Greenberg, M. T., Blair, C., \& Domitrovich, C. E. (2008). Executive functions and school readiness intervention: Impact, moderation, and mediation in the Head Start REDI Program. Development and Psychopathology, 20, 821-843. 
Blandon, A. Y., Calkins, S. D., \& Keane, S. P. (2010). Predicting emotional and social competence during early childhood from toddler risk and maternal behavior. Development and Psychopathology, 22, 119-132. doi:10.1017/S0954579409990307

Burchinal, M., Zaslow, L., Tarullo, L., \& Martinez-Beck, I. (2016). Quality thresholds, features, and dosage in early care and education: Discussion and conclusions. Monographs of the Society for Research in Child Development, 81, 75-87.

Chao, P., Bryan, T., Burstein, K., \& Ergul, C. (2006). Family-centered intervention for young children at-risk for language and behavior problems. Early Childhood Education Journal, 34, 147-153.

Clarke, B. L., Sheridan, S. M., \& Woods, K. L. (2009). Elements of healthy family-school relationships. In S. Christenson \& A. Reschly (Eds.), Handbook of school-family partnerships (pp. 61-79). New York, NY: Routledge.

Cochran, E., Cochran, M., \& Torp, N. (2000). Choosing high-quality child care. Cornell Cooperative Extension. Retrieved from https://ecommons.cornell.edu/handle/1813/3906

Conners-Burrow, N. A., Whiteside-Mansell, L., Mckelvey, L., Virmani, E. A., \& Sockwell, L. (2012). Improved classroom quality and child behavior in an Arkansas early childhood mental health consultation pilot project. Infant Mental Health Journal, 33, 256-264.

Cook, C. R., Miller, F. G., Fiat, A., Renshaw, T., Frye, M., Joseph, G., \& Decano, P. (2017). Promoting secondary teachers' well-being and intentions to implement evidence-based practices: Randomized evaluations of the achiever resilience curriculum. Psychology in the Schools, 54(1), 13-28.

Cooper, C. W. (2009). Parent involvement, African American mothers, and the politics of educational care. Equity \& Excellence in Education, 43, 379-394.

Denham, S. A., Blair, K. A., DeMulder, E., Levitas, J., Sawyer, K., Auerbach-Major, S., \& Queenan, P. (2003). Preschool emotional competence: Pathways to social competence? Child Development, 74, 238-256. doi:10.1111/1467-8624.00533

Denham, S. A., \& Brown, C. (2010). "Plays nice with others": Social-emotional learning and academic success. Early Education and Deve/opment, 21, 652-680.

Djambazova-Popordanoska, S. (2016). Implications of emotion regulation on young children's emotional wellbeing and educational achievement. Educational Review, 68, 497-515. doi:10.1080/0013 1911.2016.1144559

Domitrovich, C. E., Cortes, R. C., \& Greenberg, M. T. (2007). Improving young children's social and emotional competence: A randomized trial of the preschool "PATHS" curriculum. Journal of Primary Prevention, 28, 67-91. doi: 10.1007/s10935-007-0081.0

Downer, J. T., \& Pianta, R. C. (2006). Academic and cognitive functioning in first grade: Associations with earlier home and child care predictors and with concurrent home and classroom experiences. School Psychology Review, 35, 11-30.

Downer, J. T., Williford, A. P., Bulotsky-Shearer, R. J., Vitiello, V. E., Bouza, J., \& Reilly, S. (2018). Using data-driven, video-based early childhood consultation with teachers to reduce children's challenging behaviors and improve engagement in preschool classrooms. School Mental Health, 10, 226-242.

Dunst, C. J., \& Dempsey, I. (2007). Family professional partnerships and parenting competence, confidence and enjoyment. International Journal of Disability, Development and Education, 54, 305-318.

Dunst, C. J., \& Espe-Sherwindt, M. (2016). Family-centered practices in early childhood intervention. In B. Reichow, B. Boyd, E. Barton, S. L. Odom (Eds.), Handbook of early childhood special education (pp. 37-55). Cham, Switzerland: Springer International. 
Edwards, C. P., Sheridan, S. M., \& Knoche, L. (2010). Parent-child relationships in early learning. In E. Baker, P. Peterson, \& B. McGaw (Eds.), International encyclopedia of education (Vol. 5, pp. 438443). Oxford, England: Elsevier.

Enchautegui, M. E. (2013). Nonstandard work schedules and the well-being of low-income families. Washington, DC: Urban Institute.

Evans, G. W. (2006). Child development and the physical environment. Annual Review of Psychology, 57, 423-451. doi:10.1146/annurev.psych.57.102904.190057

Flook, L., Goldberg, S. B., Pinger, L., \& Davidson, R. J. (2014). Promoting prosocial behavior and selfregulatory skills in preschool children through a mindfulness-based kindness curriculum. Developmental Psychology, 51, 44-51.

Flook, L., Smalley, S. L., Kitil, J. M., Galla, B. M., Kaiser-Greenland, S., Locke, J., . . Kasari, C. (2010). Effects of mindful awareness practices on executive functions in elementary school children. Journal of Applied School Psychology, 26, 70-95.

Fox, L., Dunlap, G., Hemmeter, M. L., Joseph, G. E., \& Strain, P. S. (2003). The teaching pyramid: A model for supporting social competence and preventing challenging behavior in young children. Young Children, 58(4), 48-52.

Friend, M., \& Cook, L. (2006). Interactions: Collaboration skills for school pnfessionals. Boston, MA: Allyn $\&$ Bacon.

Gilliam, W. S. (2008). Implementing policies to reduce the likelihood of preschool expulsion. Foundation for Child Development (FCD) Policy Brief: Advancing PK-3, No. 7.

Gilliam, W. S. (2010, June 15). Pre-kindergartners left behind: Expulsion rates in state prekindergarten systems. The Foundation for Child Development. Retrieved from http://fed-us.org/sites/default/ files/ExpulsionCompleteReport.pdf

Gilliam, W. S., Maupin, A. N., \& Reyes, C. R. (2016). Early childhood mental health consultation: Results of a statewide random-controlled evaluation. Journal of the American Academy of Child \& Adolescent Psychiatry, 55, 754-761.

Goelman, H., \& Guo, H. (1998). What we know and what we don't know about burnout among early childhood care providers. Child and Youth Care Forum, 27, 175-199.

Gottman, J. M., Katz, L. F., \& Hooven, C. (1996). Parental meta-emotion philosophy and the emotional life of families: Theoretical models and preliminary data. Journal of Family Psychology, 10, 243-268.

Hamre, B. K., \& Pianta, R. C. (2001). Early teacher-child relationships and the trajectory of children's school outcomes through eighth grade. Child Development, 72, 625-638.

Hamre, B. K., \& Pianta, R. C. (2004). Self-reported depression in nonfamilial caregivers: Prevalence and associations with caregiver behavior in child-care settings. Early Childhood Research Quarterly, 19, 297-318.

Hamre, B. K., Pianta, R. C., Mashburn, A. J., \& Downer, J. T. (2012). Promoting young children's social competence through preschool PATHS curriculum and My Teaching Partner professional development resources. Early Education and Development, 23, 809-832. doi:10.1080/10409289.2011 .607360

Han, H. S. (2014). Supporting early childhood teachers to promote children's social competence: Components for best professional development practices. Early Childhood Education Journal, 42, 171-179.

Hanft, B. E., Rush, D. D., \& Shelden, M. L. (2004). Coaching families and colleagues in early childhood. Baltimore, MD: Brookes. 
Hatton-Bowers, H., Calvi, J., Chen, F., Foged, J., Gottschalk, C., \& Werth, L. (September, 2018) A multidimensional perspective of the effects of a mindfulness intervention on the well-being of early childhood teachers. Poster presented at the 48th meeting of the International Society of Psychoneuroendocrinology, Irvine, CA.

Hemmeter, M. L., Snyder, P. A., Fox, L., \& Algina, J. (2016). Evaluating the implementation of the Pyramid Model for promoting social-emotional competence in early childhood classrooms. Topics in Early Childhood Special Education, 36, 133-146.

Hyson, M., Copple, C., \& Jones, J. (2006). Early childhood development and education. In W. Damon, R. M. Lerner, K. A. Renninger, \& I. E. Sigle (Eds.), Handbook of child psychology, Vol. 4. Child psychology in practice (6th ed., pp. 3-47). Hoboken, NJ: Wiley.

Jarrett, R. L., \& Caba-Rodriguez, S. (2015). “My mother didn't play about education": Low-income, African American mothers' early school experiences and their impact on school involvement for preschoolers transitioning to kindergarten. Journal of Negro Education, 84, 457-472.

Jennings, P. A. (2015). Early childhood teachers' well-being, mindfulness, and self-compassion in relation to classroom quality and attitudes towards challenging students. Mindfulness, 6, 732-743.

Jennings, P. A., \& Greenberg, M. J. (2009). The prosocial classroom: Teacher social and emotional competence in relation to student and classroom outcomes. Review of Educational Research, 79, 491525.

Jeon, H. J., Kwon, K.-A., Burnham, M. M., \& Choi, Y.-J. (2019). Relations of early childhood education teachers' depressive symptoms, job-related stress, and professional motivation to beliefs about children and teaching practices. E-arly Education and Development, 30, 131-141.

Keane, S. P., \& Calkins, S. D. (2004). Predicting kindergarten peer social status from toddler and preschool problem behavior. Journal of Abnormal Child Psychology, 32, 409-423.

King, E. K., Johnson, A. V., Cassidy, D. J., Wang, Y. C., Lower, J. K., \& Kintner-Duffy, V. T. (2016). Preschool teachers' financial well-being and work time supports: Associations with children's emotional expressions and behaviors in classrooms. Early Childhood Education Journal, 44, 545553. doi:10.1007/s10643-015-0744-z

Knoche, L. L., Marvin, C. A., \& Sheridan, S. M. (2015). Strategies to support parent engagement during home visits in Early Head Start and Head Start. NHSA Dialog: The Research-to-Practice Joumal for the Early Education Field, 18, 19-42.

Knoche, L. L., Sheridan, S. M., Clarke, B. L., Edwards, C. P., Marvin, C. A., Cline, K. D., \& Kupzyk, K. A. (2012). Getting Ready: Results of a randomized trial of a relationship-focused intervention on the parent-infant relationship in early head start. Infant Mental Health Journal, 33, 439-458.

Korfmacher, J., Green, B., Spellman, M., \& Thornburg, K. R. (2007) . The helping relationship and program participation in early childhood home visiting. Infant Mental Health Journal, 28, 459-480.

Kusche, C. A., \& Greenberg, M. T. (1994). The PATHS curriculum. Seattle, WA: Developmental Research Programs.

Kwon, K.-A., Jeon, L., Ellis, N., Kile, M., Randall, K., Malek, A., \& Savatore, A. (2019, March). Happy Teacher Project: Supporting whole teacher's well-being. Panel presented at the Network of Infant/Toddler Researchers Consortium meeting, Baltimore, MD.

Landry, S. H., Smith, K. E., \& Swank, P. R. (2003). The importance of parenting during early childhood for school-age development. Developmental Neuropsychology, 24, 559-591.

Loop, L., \& Roskam, I. (2016). Do children behave better when parents' emotion coaching practices are stimulated? A micro-trial study. Journal of Child and Family Studies, 25, 2223-2235. doi:10.1007/ x10826-016-0382-0 
Ma, X., Shen, J., Krenn, H. Y., Hu, S., \& Yuan, J. (2016). A meta-analysis of the relationship between learning outcomes and parental involvement: During early childhood education and early elementary education. Educational Psychology Review, 28, 771-801.

Maguire, L., Niens, U., McCann, M., \& Connolly, P. (2015). Emotional development among early school-age children: Gender differences in the role of problem behaviors. Educational Psychology, $36,1-21$.

McCollum, J. A., \& Yates, T. J. (1994). Dyad as focus, triad as means: A family-centered approach to supporting parent-child interactions. Infants and Young Children, 6, 54-63.

Menting, A., Orobio de Castro, B., \& Matthys, W.(2013). Effectiveness of the Incredible Years parent training to modify disruptive and prosocial child behavior: A meta-analytic review. Clinical Psychology Review, 33, 901-913.

Meyer, S., Raikes, H. A., Virmani, E. A., Waters, S., \& Thompson, R. A. (2014). Parent emotional representations and the socialization of emotion regulation in the family. International Journal of Behavioral Development, 38, 164-173. doi:10.1177/0165025413519014

Morgan, H. (2019). Does high-quality preschool benefit children: What the research shows. Education Sciences, 9(1), 19. doi:10.3390/educsci9010019

Oberle, E., \& Schonert-Reichl, K. A. (2017). Social and emotional learning: Recent research and practical strategies for promoting children's social and emotional competence in schools. In J. Matson (Ed.), Handbook of social behavior and skills in children (pp. 175-197). New York, NY: Springer International.

Odom, S. L., McConnell, S. R., \& Brown, W. H. (2008). Social competence of young children: Conceptualization, assessment, and influences. In W. H. Brown, S. L. Odom, \& S. R. McConnell (Eds.), Social competence of young children: Risk, disability, and intervention (pp. 31-59). Baltimore, MD: Paul H. Brookes.

Owen, S. (2016). Professional learning communities: Building skills, reinvigorating the passion, and nurturing teacher wellbeing and "flourishing" within significantly innovative schooling contexts. Educational Review, 68, 403-419.

Pandey, A., Hale, D., Das, S., Goddings, A.-L., Blakemore, S. J., \& Viner, R M. (2018). Effectiveness of universal self-regulation-based interventions in children and adolescents: A systematic review and meta-analysis. JAMA Pediatrics, 172, 566-575. doi:10.1001/jamapediatrics.2018.0232

Perry, D. F., Allen, M. D., Brennan, E. M., \& Bradley, J. R. (2010). The evidence base for mental health consultation in early childhood settings: A research synthesis addressing children's behavioral outcomes. Early Education and Development, 21, 795-824.

Phillips, D., Austin, L. J. E., \& Whitebook, M. (2016). The early care and educator workforce. The Future of Children, 26, 139-158.

Pianta, R. C., Clifford, R., Burchinal, M., Bryant, D., Clifford, R., Early, D., \& Barbarin, O. A. (2005). Features of pre-kindergarten programs, classrooms, and teachers: Do they predict observed classroom quality and child-teacher interactions? Applied Developmental Science, 9, 144-159.

Powell, D. R., Son, S.-H., File, N., \& San Juan, R. R. (2010). Parent-school relationships and children's academic and social outcomes in public school pre-kindergarten. Journal of School Psychology, 48, 269-292. doi:10.1016/j.jsp.2010.03.002

Price, D., \& McCallum, F. (2015). Ecological influences on teachers' wellbeing and "fitness." AsiaPacific Journal of Teacher Education, 43, 195-209.

Robert Wood Johnson Foundation. (2016, March 1). Can early childhood interventions improve health and well-being? Health Policy in Brief. Retrieved from https://www.rwjf.org/en/library/research/2016/03/can-early-childhood-interventions-improve-life-outcomes-html 
Roberts, A., LoCasale-Crouch, J., Hamre, B., \& DeCoster, J. (2016). Exploring teachers' depressive symptoms, interaction quality, and children's social-emotional development in Head Start. Early Education and Development, 27, 642-654.

Russell, B. S., Lee, J. O., Spieker, S., \& Oxford, M. L. (2016). Parenting and preschool self-regulation as predictors of social emotional competence in 1st grade. Journal of Research in Childhood Education, 30, 153-169.

Schonert-Reichel, K. A., \& Hymel, S. (2007). Educating the heart as well as the mind: Social and emotional learning for school and life success. Education Canada, 47, 20-25.

Scott-Little, C., Kagan, S. L., \& Frelow, V. S. (2006). Conceptualization of readiness and the content of early learning standards: The intersection of policy and research? Early Childhood Research Quarterly, 21, 153-173.

Semple, R. J., Droutman, V., \& Reid, B. A. (2017). Mindfulness goes to school: Things learned (so far) from research and real-world experiences. Psychology in the Schools, 54, 29-52.

Sheridan, S. M., \& Kratochwill, T. R. (2008). Conjoint behavioral consultation: Promoting family-school connections and interventions. New York, NY: Springer.

Sheridan, S. M., Knoche, L. L., Edwards, C. P., Bovaird, J. A., \& Kupzyk, K. A. (2010). Parent engagement and school readiness: Effects of the Getting Ready intervention on preschool children's socialemotional competencies. Early Education and Development, 21, 125-156.

Sheridan, S. M., Knoche, L. L., Edwards, C. P., Kupzyk, K. A., Clarke, B. L., \& Kim, E. M. (2014) . Efficacy of the Getting Ready Intervention and the role of parental depression. Early Education and Development, 25, 746-769.

Sheridan, S., Marvin, C., Knoche, L., \& Edwards, C. (2008). Getting ready: Promoting school readiness through a relationship-based partnership model. Early Childhood Intervention Services, 2, 149 172 .

Shonkoff, J. P., Garner, A. S., Siegel, B. S., Dobbins, M. I., Earls, M. F., McGuinn, L., . . Wood, D. L. (2012). The lifelong effects of early childhood adversity and toxic stress. Pediatrics, 129, e232-e246.

Sisask, M., Värnik, P., Värnik, A., Apter, A., Balazs, J., Balint, M., . . Cosman, D. (2014). Teacher satisfaction with school and psychological wellbeing affects their readiness to help children with mental health problems. Health Education Journal, 73, 382-393.

Snyder, T. D., \& Dillow, S. A. (2015). Digest of education statistics 2013 (NCES 2015-011). National Center for Education Statistics, Institute of Education Sciences. Retrieved from https://nces.ed.gov/ pubs2015/2015011.pdf

Thompson, R. (2016). What more has been learned? The science of early childhood development 15 years after "Neurons to Neighborhoods." Zero to Three, 36(3), 18-24.

Torquati, J., Raikes, H., \& Huddleston-Casas, C. A. (2007). Teacher education, motivation, compensation, workplace support, and links to quality of center-based child care and teachers' intention to stay in the early childhood profession. Early Childhood Research Quarterly, 22, 261-275.

Trivette, C. M., Dunst, C. J., Boyd, K., \& Hamby, D. (1996). Family-oriented program models, helpgiving practices and parental control appraisals. Exceptional Children, 62, 237-248.

Wachs, T. D., Gurkas, P., \& Kontos, S. (2004). Predictors of preschool children's compliance behavior in early childhood classroom settings. Journal of Applied Developmental Psychology, 25, 439-457.

Watamura, S. E., Phillips, D. A., Morrissey, T. W., McCartney, K., \& Bub, K. L. (2011). Double jeopardy: Poorer social-emotional outcomes for children in the NICHD SECCYD experiencing home and child-care environments that confer risk. Child Development, 82, 48-65.

Webster-Stratton, C. (1992). The Incredible Years: A trouble-shooting guide for parents of children ages 3-8 years. Toronto, Canada: Umbrella Press. 
Webster-Stratton, C. (1998). Preventing conduct problems in Head Start children: Strengthening parent competencies. Journal of Consulting and Clinical Psychology, 66, 715-730.

Webster-Stratton, C., Reid, M. J., \& Stoolmiller, M. (2008). Preventing conduct problems and improving school readiness: Evaluation of the Incredible Years Teacher and Child Training Programs in high-risk schools. Journal of Child Psychology and Psychiatry, 19, 471-488. doi:10.1111/j.1469-7610 .2007.01861.x

Weissberg, R. P., Durlak, J. A., Domitrovich, C. E., \& Gullotta, T. P. (2015). Social and emotional learning: Past, present, and future. In J. A. Durlak, C. E. Domitrovich, R. P. Weissberg, \& T. P. Gullotta (Eds.), Handbook for social and emotional learning: Research and practice (pp. 3-19). New York, NY: Guilford.

Werner, C. D., Linting, M., Vermeer, H. J., \& Van IJzendoorn, M. H. (2015). Noise in center-based child care: Associations with quality of care and child emotional wellbeing. Journal of Environmental Psychology, 42, 190-201. 